\title{
A inconstitucionalidade do toque de recolher estadual e municipal
}

\author{
The unconstitutionality of state and municipal curfews \\ La inconstitucionalidad del toque de queda estatal y municipal
}

\section{Resumo}

O presente artigo não tem a intenção de analisar a necessidade ou a efetividade das medidas restritivas de locomoção e de distanciamento social como métodos de enfrentamento a pandemia do COVID-19, esses aspectos não serão analisados. Esse artigo visa apenas a analisar os aspectos jurídicos constitucionais, do toque de recolher, haja vista a sua natureza jurídica e sua atual aplicação pelos entes da federação, como os estados e os municípios. Nesse sentido, o presente texto será desenvolvido numa perspectiva de análise da aplicação de recurso jurídico constitucional denominado "toque de recolher" que possui regras de criação e de aplicação claramente predeterminadas. Desta maneira, seguir-se-á um estudo a partir de levantamento de literatura onde autores conceituam e discutem sobre a temática em tela, trazendo o percurso histórico do toque de recolher até sua aplicação nos dias atuais, dando-se ênfase aos aspectos ligados aos direitos fundamentais como vetor para aclarar a constitucionalidade do citado instrumento utilizado como meio de contenção da propagação do coronavírus.

Palavras-chave: Toque de recolher; COVID-19; Direitos fundamentais.

\begin{abstract}
The present article does not intend to analyze the necessity or effectiveness of the measures restricting locomotion and social distancing as methods of confronting the COVID-19 pandemic, these aspects will not be analyzed. This article aims only to analyze the constitutional legal aspects of curfew, in view of its legal nature and its current application by the entities of the federation, such as states and municipalities. In this sense, the present text will be developed in a perspective of analysis of the application of the constitutional legal resource called "curfew", which has clearly predetermined rules of creation and application. Thus, a study will follow from a survey of literature where authors conceptualize and discuss the theme in question, bringing the historical path of curfew until its application today, emphasizing the aspects linked to fundamental rights as a vector to clarify the constitutionality of this instrument used as a means of containing the spread of coronavirus.
\end{abstract}

Keywords: Curfew; COVID-19; Fundamental rights.

\section{Resumen}

Este artículo no pretende analizar la necesidad o la eficacia de las medidas de restricción de la locomoción y de distanciamiento social como métodos para afrontar la pandemia de COVID-19, estos aspectos no serán analizados. El 
presente artículo sólo pretende analizar los aspectos jurídicos constitucionales del toque de queda, dada su naturaleza jurídica y su aplicación actual por parte de las entidades de la federación, como los estados y los municipios. En este sentido, este texto se desarrollará en una perspectiva de análisis de la aplicación del recurso jurídico constitucional denominado "toque de queda" que tiene unas reglas de creación y aplicación claramente predeterminadas. Así, se realizará un estudio a partir de un relevamiento bibliográfico donde los autores conceptualizan y discuten sobre el tema en cuestión, trayendo el recorrido histórico del toque de queda hasta su aplicación en la actualidad, haciendo hincapié en los aspectos relacionados con los derechos fundamentales como vector para esclarecer la constitucionalidad del citado instrumento utilizado como medio de contención de la propagación del coronavirus.

Palabras clave: Toque de queda; COVID-19; Derechos fundamentales.

\section{Introdução}

A discussão em tela tem o intuito de promover um debate teórico a respeito dos aspectos jurídicos da adoção do toque de recolher decretado por estados e municípios brasileiros, abordando a bibliografia acerca do tema, e evidenciando a inconstitucionalidade de tais medidas que acarretam em restrições a locomoção de pessoas em determinados horários, visando conter as infecções relativas ao novo coronavírus.

De início é necessário abordar o conceito do toque de recolher, tanto em sentido amplo quanto em sentido estrito, para a observação de sua aplicação e análise de sua validade perante a Constituição Federal/88, enumerando os requisitos de sua aplicabilidade e destacando as normas infraconstitucionais que ensejaram o uso desse instituto para a contenção da propagação do coronavírus.

De outra maneira, é importante trazer à baila a Lei n. 13.979/20 que trouxe importantes regramento para o período pandêmico. Diante disso faz-se necessário disseca-la, tendo em vista a necessidade de obter a interpretação adequada da norma, bem como sua real aplicação, fazendo também o comparativo com o instituto em comento largamente utilizado no combate a Covid-19.

Ademais, analisar-se-á os aspectos constitucionais a serem assegurados nesse período, apresentando até onde pode o Estado ir quando se trata assegurar garantias e proteger vidas humanas. Importante que se perceba os limites conferidos ao Estado, e seja examinado suas implicações para o ordenamento jurídico brasileiro.

\section{Metodologia}

Durante a pesquisa efetivada para construção deste artigo, foi imprescindível seguir as regras procedimentais para confecção de estudos científicos. Assim, observa-se necessária a utilização de uma metodologia determinada, uma vez que a partir dela pode-se balizar a problemática e objetivos com a escopo de se obter bases que indicarão resultados sobre a temática levantada.

Assim, o estudo tem estilo descritivo, ou seja, a pesquisa é qualitativa, pois almeja a compreensão ampla do fenômeno que está sendo analisado. Diante disso, considera-se que todos os dados da realidade são formidáveis e devem ser verificados, vez que o ambiente e as pessoas nele inseridas devem ser olhados holisticamente: não são reduzidos a variáveis, mas observados como um todo Godoy (1995).

A pesquisa foi norteada, também, pelo método indutivo, cuja aproximação dos fenômenos é direcionada para planos cada vez mais abrangentes, indo das constatações mais particulares às leis e teorias (conexão ascendente); método que considera o conhecimento como baseado na experiência; a generalização deriva de observações de casos da realidade concreta e são elaboradas a partir de constatações particulares Pereira (2018).

Desta forma, é possível verificar tal aplicabilidade do método pela análise legal e jurisprudencial relacionada à matéria. 
Ainda, quanto à pesquisa bibliográfica realizada, Lakatos e Marconi (2001) ensinam que a pesquisa bibliográfica, ou de fontes secundárias, abrange toda bibliografia já tornada pública em relação ao tema de estudo, desde publicações avulsas, boletins, jornais, revistas, livros, pesquisas, monografias, teses, material cartográfico etc., até meios de comunicação orais: rádio, gravações em fita magnética e audiovisuais: filmes e televisão. Sua finalidade é colocar o pesquisador em contato direto com tudo o que foi escrito, dito ou filmado sobre determinado assunto, inclusive conferências seguidas de debates que tenham sido transcritos por alguma forma, querem publicadas, quer gravadas.

Desta forma, a pesquisa tem como parâmetro a utilização de revisão bibliográfica, análise legislativa e jurisprudencial sobre o assunto, sendo que a investigação é realizada por meio da identificação de conceitos, normas e princípios fundamentais que denotam sua relevância e utilidade para o direito processual civil brasileiro.

\section{Resultados e Discussão}

\subsection{Os Direitos Fundamentais}

A evolução histórica dos Direitos Fundamentais foi extensa e tortuosa. Os mesmos não foram criados de uma só vez, foram evolucionando e se consolidando no transcorrer da vivência humana social. Os Direitos Fundamentais estão ligados à determinação de barreiras ao poder estatal e a proteção dos direitos dos indivíduos, a fim de que os mesmos sejam protegidos.

Os mencionados direitos surgiram em meio às revoluções americana e francesa no século XVIII, foi um marco para a o surgimento do Estado Moderno e de Direito. BOBBIO 1992 menciona que os direitos do homem, por mais fundamentais que sejam, são direitos históricos, ou seja, nascidos em certas circunstâncias, caracterizados por lutas em defesa de novas liberdades contra velhos poderes, e nascidos de modo gradual, não todos de uma vez e nem de uma vez por todas.

Bonavides (1993) escreve que o lema revolucionário do século XVIII, esculpido pelo gênio político francês, exprimiu em três princípios cardeais todo o conteúdo possível dos direitos fundamentais, profetizando até mesmo a sequência histórica de sua gradativa institucionalização: liberdade igualdade e fraternidade. Com efeito, descoberta a forma da generalização e universalidade, restava doravante seguir os caminhos que consentissem inserir na ordem jurídica positiva de cada ordenamento político os direitos e conteúdo materiais referentes àqueles postulados. Os direitos fundamentais passaram na ordem institucional a manifestar-se em três gerações sucessivas, que traduzem sem dúvida um processo cumulativo e qualitativo, o qual, segundo tudo faz prever, tem por bússola uma nova universalidade: a universalidade material e concreta, em substituição da universalidade abstrata e, de certo modo, metafísica daqueles direitos, contida no jusnaturalismo do século XVIII.

Ainda nesse sentido, a Declaração dos Direitos Humanos das Nações Unidas, no seu artigo 29 traz todo o homem tem deveres para com a comunidade, na qual o livre e pleno desenvolvimento de sua personalidade é possível. No exercício de seus direitos e liberdades, todo o homem estará sujeito apenas às limitações determinadas pela lei, exclusivamente com o fim de assegurar o devido reconhecimento e respeito dos direitos e liberdades de outrem e de satisfazer as justas exigências da moral, da ordem pública e do bem-estar de uma sociedade democrática. Esses direitos e liberdades não podem, em hipótese alguma, ser exercidos contrariamente aos objetivos e princípios das Nações Unidas. Nenhuma disposição da presente Declaração pode ser interpretada como o reconhecimento a qualquer Estado, grupo ou pessoa, do direito de exercer qualquer atividade ou praticar qualquer ato destinado à destruição de quaisquer direitos e liberdades aqui estabelecidos.

Assim, observa-se a escalada histórica até que fossem estabelecidas garantias fundamentais a todo homem, de modo a trazer limitação ao poder estatal a fim de que este não mais haja com violações contra a vida humana e suas liberdades, se abstendo, consequentemente, de ferir sua dignidade.

\subsection{A dignidade da pessoa humana}

A constituição federal de 1988 assegurou o exercício dos direitos fundamentais e direitos sociais, bem como a 
liberdade e a igualdade. Barroso (2013) menciona que dignidade da pessoa humana é o valor intrínseco de todos os seres humanos, assim como a autonomia de cada indivíduo e limitada por algumas restrições legítimas impostas a ela em nome de valores sociais ou interesses estatais (valor comunitário).

A noção de dignidade da pessoa humana pode ser concebida em dois enfoques, sendo primeiro que serve de mecanismo de proteção individual, tanto com relação aos outros indivíduos como também frente ao Estado e o segundo, constitui dever fundamental de tratamento igualitário dos próprios semelhantes.

Moraes (2020) cita que um valor espiritual e moral inerente à pessoa, que se manifesta singularmente na autodeterminação consciente e responsável da própria vida e que traz consigo a pretensão ao respeito por parte das demais pessoas, constituindo-se um mínimo invulnerável que todo estatuto jurídico deve assegurar de modo que, somente excepcionalmente, possam ser feitas limitações ao exercício dos direitos fundamentais, mas sempre sem menosprezar a necessária estima que merecem todas as pessoas enquanto seres humanos e a busca ao Direito à Felicidade.

Kant (1980) traz que a moralidade, e a humanidade enquanto capaz de moralidade, são as únicas coisas que têm dignidade. A destreza e a diligência no trabalho têm um preço venal; a argúcia de espírito, a imaginação viva e as fantasias têm um preço de sentimento; pelo contrário, a lealdade nas promessas, o bem-querer fundado em princípios (e não no instinto) têm um valor íntimo. A natureza bem como a arte nada contêm que à sua falta se possa pôr em seu lugar, pois que o seu valor não reside nos efeitos que delas derivam, na vantagem e utilidade que criam, mas sim nas intenções, isto é nas máximas da vontade sempre prestes a manifestar-se desta maneira por ações, ainda que o êxito as não favorecesse.

\subsection{Lei $\mathrm{n}^{\circ}$ 13.979, de 6 de fevereiro de 2020 e as medidas de enfrentamento ao covid-19}

Com o surgimento da COVID-19 e sua transmissão entre humanos e a proliferação da mesma em terras brasileiras, o governo federal editou a Lei n ${ }^{\circ} 13.979$, que "Dispõe sobre as medidas para enfrentamento da emergência de saúde pública de importância internacional decorrente do coronavírus responsável pelo surto de 2019”.

A referida lei impõe isolamento, quarentena, requisição de bens e outras coisas, entretanto em nenhum momento existe alguma menção a possibilidade de decretação de toque de recolher ou de lockdown.

Atendo-se ao tema, observa-se que no art. $3^{\circ}$ existe a possibilidade de cerceamento de locomoção entre estado e entre municípios, entretanto inexiste determinação a respeito de locomoção intramunicipal. Na lei também não se encontra nenhuma menção a possibilidade de prisão do cidadão ao ser encontrado descumprindo o toque de recolher.

\subsection{O que é toque de recolher e a inconstitucionalidade de sua ocorrência}

A nomenclatura toque de recolher advém do francês arcaico covrefeu, que significa "cobrir o fogo". Posteriormente, foi uma prática aplicada no continente europeu durante a segunda guerra mundial. Tal ato consistia em que determinado horário da noite, uma sirene tocava e todos os residentes da localidade deveriam se recolher em suas residências. Brenner 1999 cita que a medida também foi bastante utilizada na Alemanha Nazista em meados de 1933 a 1945 em perseguição aos judeus, como forma de repressão social.

$\mathrm{O}$ toque de recolher se tornou uma medida aplicada pelo judiciário para restringir a locomoção de pessoas durante determinado intervalo de tempo no dia, geralmente durante o período noturno. Anteriormente essa medida era usada em cidades com um alto índice de violência, onde a restrição às saídas apenas se aplicavam as crianças e adolescentes. Saliba, Brega Filho (2012).

Hoje o toque de recolher mudou sua roupagem, o objetivo não é mais conter a violência, como um foco principal de sua aplicação imediata, mas impedir a disseminação do novo coronavírus (COVID-19).

Araújo (2021) aduz que a quarentena não se identifica, com o denominado toque de recolher. Segundo definição do 
Dicionário de Língua Portuguesa Aurélio, quarentena significa "[Medicina] isolamento de certas pessoas, lugares e animais que podem acarretar perigo de infecção, o período de quarentena é relativo e depende do tempo necessário para proteção contra a propagação de uma doença determinada.

Juridicamente, a quarentena é medida sanitária que visa reduzir a transmissibilidade da COVID-19, cuja aplicação exige, necessariamente, fundamentação em dados científicos. A quarentena para enfrentamento da COVID-19 encontra-se disciplinada na Lei 13.973/2020, na Portaria ${ }^{\circ}$ 356/2020/GM/MS e na Portaria Interministerial $n^{\circ}$ 09, de27/05/2020 (que revogou a Portaria Interministerial $n^{\circ}$, de 17/03/2020).

Já o denominado toque de recolher, segundo definição contida no Dicionário Priberam Língua Portuguesa consiste em "proibição, determinada como medida excecional por governo ou autoridade, de permanecer na rua a partir de determinada hora". O toque de recolher se caracteriza como limitação genérica e abstrata, sem qualquer base em evidências científicas e em análises sobre as informações estratégicas em saúde.

Amparado pela Constituição/88 é possível observar pelo artigo 5, XV da Carta Magna que: "é livre a locomoção no território nacional em tempo de paz, podendo qualquer pessoa, nos termos da lei, nele entrar, permanecer ou dele sair com seus bens". Para que a livre locomoção seja proibida no Brasil algumas condições devem se concretizar, tais como a adoção do Estado de Defesa e Estado de Sítio que são situações extremas, e mesmo com a adoção de tais medidas no Estado de Defesa ainda é possível manter sua liberdade de ir e vir, segundo o constituinte originário. (ADI 6788)

Para que o toque de recolher seja constitucionalmente aplicável é necessário perfazer algumas exigências, previstas no artigo 137, caput, da Constituição Federal de 88, a saber:

Art. 137. O Presidente da República pode, ouvidos o Conselho da República e o Conselho de Defesa Nacional, solicitar ao Congresso Nacional autorização para decretar o estado de sítio nos casos de:

I - comoção grave de repercussão nacional ou ocorrência de fatos que comprovem a ineficácia de medida tomada durante o estado de defesa;

II - declaração de estado de guerra ou resposta a agressão armada estrangeira.

Parágrafo único. O Presidente da República, ao solicitar autorização para decretar o estado de sítio ou sua prorrogação, relatará os motivos determinantes do pedido, devendo o Congresso Nacional decidir por maioria absoluta.

O Estado Democrático de Direito é sedimentado pela soberania, pela cidadania, dignidade da pessoa humana e que o poder emana do povo, que escolhe representantes para cada cargo, sendo que os mesmos recebem competências determinadas, tudo previsto no art. $1^{\circ}$ da Constituição Federal.

Assim observando as determinações legais prescritas na Constituição Federal/88, observa-se que não cabe a qualquer ente federado editar normas ou aumentar seus próprios poderes. As permissões legais do cargo são concedidas pela Constituição e pelas leis, sendo vedada um voluntarismo concessor de poder.

O princípio da legalidade, sedimentado no artigo $5^{\circ}$ da Constituição Federal/88, é límpido ao mencionar que "ninguém será obrigado a fazer ou deixar de fazer alguma coisa senão em virtude de lei”, trazendo assim uma garantia constitucional de liberdade.

O toque de recolher não possui uma definição explícita constitucionalmente, mas segundo a Constituição Federal/88 ao tratar sobre o Estado de Sítio, mostra a situação em que tal medida seria aplicável, no caso, no artigo 139, I, da CF/88 tratando da obrigação de permanência em localidade determinada, e ainda sobre a detenção de edifícios não destinados a acusados ou condenados por crimes comuns, de acordo com o artigo 139, II. Sendo corroborado por Lenza (2021) ele elucida que por sua vez, no caso estado de sítio decretado com fundamento no art. 137, I, poderão ser tomadas contra as pessoas as medidas de obrigação de permanência em localidade determinada (art. 139, I); detenção em edifício não destinado a acusados ou condenados por crimes comuns (art. 139, II); suspensão da liberdade de reunião (art. 139, IV). Vejamos: 
Art. 138. O decreto do estado de sítio indicará sua duração, as normas necessárias a sua execução e as garantias constitucionais que ficarão suspensas, e, depois de publicado, o Presidente da República designará o executor das medidas específicas e as áreas abrangidas.

$\S 1^{\circ} \mathrm{O}$ estado de sítio, no caso do art. 137, I, não poderá ser decretado por mais de trinta dias, nem prorrogado, de cada vez, por prazo superior; no do inciso II, poderá ser decretado por todo o tempo que perdurar a guerra ou a agressão armada estrangeira.

$\S 2^{\circ}$ Solicitada autorização para decretar o estado de sítio durante o recesso parlamentar, o Presidente do Senado Federal, de imediato, convocará extraordinariamente o Congresso Nacional para se reunir dentro de cinco dias, a fim de apreciar o ato.

$\S 3^{\circ} \mathrm{O}$ Congresso Nacional permanecerá em funcionamento até o término das medidas coercitivas.

No caso em questão normas infraconstitucionais não podem ser aplicadas sem antes considerar sua validade no plano constitucional. Ainda segundo Lenza (2021), uma norma, de hierarquia inferior, busca o seu fundamento de validade na norma superior e esta, na seguinte, até chegar à Constituição, que é o fundamento de validade de todo o sistema infraconstitucional.

Os Governadores e Prefeitos ao decretarem toque de recolher se valem da lei 13.979/2020 que dispõe sobre as medidas de enfretamento a saúde pública decorrente da pandemia do Coronavírus, que em nenhum momento permite a instituição de toque recolher.

Como já mencionado, o cidadão não é obrigado a cumprir algo que não existe na lei, ou seja, que tudo aquilo que não está proibido por lei é juridicamente permitido.

Ora, se uma lei busca sua validade imediata na Constituição, e não encontra o amparo constitucional, nos deparamos com uma Inconstitucionalidade de vício material, decorrente de matéria que afronte a constituição Lenza (2021).

\section{Considerações Finais}

A decretação de toque de recolher contraria o texto constitucional, que assegura a liberdade de locomoção no território nacional em tempos de paz. Ademais, a lei em questão prevê a possibilidade de os entes federados restringirem esse direito, mas nada fala sobre possíveis restrições intramunicipais. Não se pode esquecer que todo o ordenamento jurídico infraconstitucional deve ser interpretado de acordo com o texto da Constituição Federal/88, respeitando os princípios e os direitos fundamentais.

Nesta senda, entende-se que o toque de recolher só pode ser aplicado quando se enquadrar nas hipóteses cabíveis do art. 137, I da CF de 88, durante a decretação do Estado de Sítio pelo Presidente da República com a chancela do Congresso Nacional, o qual possui, inclusive, a competência exclusiva para autorizar o Estado de Sítio.

Em sendo assim, compreende-se que os governadores e prefeitos além de ultrapassarem suas atribuições, estão atingindo e usurpando a competência do Presidente da República e do Congresso Nacional ao limitarem o direito de ir e vir da população, por meios infraconstitucionais ao produzir decretos inconstitucionais para a contenção da propagação do coronavírus. A utilização de toque de recolher de maneira indiscriminada é um claro retorno ao autoritarismo estatal, algo que vinha sendo deixado para trás e deve continuar lá.

A criação de um regime de exceção que não possui possibilidade de aplicação constitucional é uma clara ocorrência de um confronto com a lei maior.

Os danos causados pela aplicação inconstitucional do toque de recolher devem ser analisadas por outros pesquisadores para corroborar, ou não, com o entendimento exposto nesse artigo.

\section{Referências}

Alexy, R. (1993) Teoria de Los Derechos Fundamentales. Centro de Estudios Constitucionales. 
Research, Society and Development, v. 11, n. 2, e9811221863, 2022

(CC BY 4.0) | ISSN 2525-3409 | DOI: http://dx.doi.org/10.33448/rsd-v11i2.21863

Brasil. (1988) Constituição da República Federativa do Brasil. Brasília. http://www.planalto.gov.br/ccivil_03/constituicao/constitui\%C3\%A7ao.htm.

Brasil. (2021). Ação direta de inconstitucionalidade com pedido liminar. Ministério Público Federal. http://www.mpf.mp.br/mt/sala-deimprensa/Documentos\%20para\%20link/PRMBDGMT00002116.20211.pdf

Brener, J. (1999). A Segunda Guerra Mundial: o planeta em chamas. Ática.

Carvalho, K. (2013). Direito Constitucional Positivo. Del Rey.

Cassettari, C. (2011). Elementos de Direito Civil. Saraiva.

CAVALCANTI, H et al. (2020). Toque de recolher e lockdown: a mutação inconstitucional promovida pelas autoridades locais no combate à Covid-19 no Brasil. Prim@ Facie, 19(42),463-489.

Coelho, F. (2009). Curso de Direito Civil. Parte Geral. Saraiva.

Diniz, M. (2012). Curso de Direito Civil Brasileiro: Teoria Geral do Direito Civil. Saraiva.

FERREIRA FILHO, M. (2015). Curso de direito constitucional. (40a ed.), Saraiva.

Kelsen, H. (2001). Teoria pura do direito. Tradução J. Cretella Jr. e Agnes Cretella. Ed. RT.

Lafer, C. (1988). A reconstrução dos direitos humanos: um diálogo com o pensamento de Hannah Arendt. Companhia das Letras.

Leite, J. \& Ayala, P. (2002). Direito Ambiental na Sociedade de Risco. Forense Universitária.

Loewenstein, K. (1982). Teoría de la Constitución - Traducción y Estudio sobre la obra por Alfredo Gallego Anabitarte. Ariel, S.A.

Lopes, A. (2001). Os Direitos Fundamentais como Limite ao Poder de Legislar. Sergio Fabris.

Luchmann, L. H. H. (2002). Possibilidades e limites da democracia deliberativa: a experiência do orçamento participativo de Porto Alegre [Master's thesis, Universidade Estadual de Campinas]. https://repositorio.ufsc.br/handle/123456789/106533

Marchi, R., \& Souza, J. (2012). O "Toque de recolher" como um retrocesso ao autoritarismo: caminhos e tendências políticas do Conselho Tutelar em Blumenau - SC (Curfew as a return to authoritarianism: paths and political trends of the.) Doi: 10.5212/Emancipacao.v.12i1.0006. Emancipação, 12(1). https://revistas2.uepg.br/index.php/emancipacao/article/view/1805

Mello, C. (1984) O conteúdo jurídico do princípio da igualdade. Ed. RT.

Nunes, R. (2002) O Princípio Constitucional da Dignidade da Pessoa Humana. Saraiva

Piovesan, F. (2006). Direitos Humanos e o Direito Constitucional Internacional. Saraiva.

Preste, C. (2003) A Dignidade Humana e o Direito de Locomoção das Pessoas Portadoras de Necessidades Especiais https://www.metodista.br/revistas/revistas-unimep/index.php/cd/article/view/835

Souza, J. (2009) O toque de recolher como um retrocesso ao autoritarismo: caminhos e tendências políticas do Conselho Tutelar em Blumenau. 2009. $60 \mathrm{f}$. Trabalho de Conclusão de Curso (Ciências Sociais). Universidade Regional de Blumenau. Blumenau.

Tavares, J. (1999) Toque de recolher para crianças e adolescentes à luz da legislação brasileira. Repositório Uniceub. Brasília, 2010. p. 11. 37 BRENER, Jayme. A Segunda Guerra Mundial: o planeta em chamas. (3a ed.), Ática.

Tavares, A. (2019). Curso de direito constitucional. (17a ed.), Saraiva Educação. 